\title{
A OPINIÃO PÚBLICA E POLÍTICAS PÚBLICAS DE EDUCAÇÃO PARA O CONSUMO: INSTRUMENTO DE TRANSFORMAÇÃO DA REALIDADE SOCIAL
}

\author{
Liton Lanes Pilau Sobrinho ${ }^{1}$
}

\section{RESUMO}

O presente artigo versa sobre a transformação da realidade social através da opinião pública e políticas públicas na educação para o consumo. Por meio deste trabalho, buscou-se analisar a conceituação de opinião pública, principalmente o conceito trazido por Luhmann, que faz uma ligação com os meios de comunicação e o processo comunicativo, pois a opinião pública, enquanto produto de constantes atualizações dos meios de comunicação, traduz-se como a própria realidade social. E nesse sentido, portanto, que, para compreender a transformação da realidade social, pretende-se analisar as condições de possibilidade de mudança social, bem como as políticas públicas de defesa dos consumidores, que irão refletir na educação para o consumo.

Palavras-chave: Educação para o Consumo. Opinião Pública. Políticas Públicas. Teoria da Comunicação.

\section{INTRODUÇÃO}

O ser humano se vale da linguagem para expressar sua manifestação de vontade, utilizando-se dos mais diversos meios de comunicação, através dos quais as informações chegam aos receptores que formaram a opinião pública sobre o que Ihes foi informado. Dessa forma, a defesa do consumidor, através do seu Código de Defesa do Consumidor - Lei 8.078 de 11 de setembro de 1990 - estabelece o fomento para criação de políticas públicas, que tem como um de seus princípios a educação para o consumo, como instrumento de transformação da realidade social.

\section{CONCEITO DE OPINIÃO PÚBLICA}

Um dos exemplos históricos mais significativos acerca do que foi compreendido enquanto opinião pública pode ser o fato ocorrido na Inglaterra de 1935, quando houve a insurgência de muitos contra o parlamento inglês, que pretendia ceder a Etiópia à Itália. Essa insurgência obrigou o governo a abandonar o projeto, prevalecendo a voz geral. Tal acontecimento veio a despertar uma consciência geral para o fenômeno que, historicamente, podia ser compreendido como a voz geral da coletividade. ${ }^{2}$ 
Contudo, a concepção de opinião pública vem desde muito antes. "Desde 1780 os escritores franceses faziam uso extensivo da opinião pública para referir-se a um fenômeno mais político que social". ${ }^{3}$ Com a criação do já referido tipo móvel de Guttemberg no século XV iniciou-se um processo de divulgação massiva de informações, viabilizando a democratização da leitura e, conseqüentemente, a ampliação da possibilidade de manifestação de opiniões. Por isso,

[...] não pode falar-se de um conceito político de "opinião pública" antes da segunda metade do século XVIII, e de sua imposição em toda a Europa inclusive depois da Revolução Francesa. Todavia, a verdadeira inovação se fala no uso da imprensa para colocar em circulação panfletos políticos, ou melhor - na Inglaterra do século XVIII - para a divulgação de petições dirigidas ao Parlamento. Porque com isto resta claro que não somente se dirigem ao destinatário e que estava excluída a manutenção de segredo. ${ }^{4}$

A rápida difusão comunicativa promovida pela imprensa aliou os interesses de comerciantes e classes dirigentes com a crescente expansão da alfabetização, possibilitando a emergência da uma voz geral, compreendida, até então, enquanto vontade política da sociedade. ${ }^{5}$ Pergunta-se, entretanto, o que é a opinião pública? Pode a expressão do pensamento coletivo ser expresso enquanto opinião pública? A compreensão do fenômeno torna por ser explicado em diferentes óticas.

Sartori traduz a opinião pública como um conjunto de idéias que residem na coletividade. A opinião pública, assim, emerge do público, para o público e envolve a coisa pública. Nessa linha de pensamento o conceito de opinião pública é traduzido enquanto a voz geral orientada à resolução de problemas coletivos, ao interesse geral da coletividade. Igualmente refere que a opinião pública não pode ser encarada como uma verdade, mas sim como opinião, eis que seria um mero opinar subjetivo, carente de comprovação. ${ }^{6}$

Já em Habermas, a opinião pública não possui o encargo de vincularse a regras políticas ou dedicar-se a discussões públicas, no entanto mantém estreita relação com o poder no momento em que toda e qualquer opinião (seja ela pública ou não) reveste-se de importância ao exercício do poder estatal. Por isso, quaisquer manifestações (opiniões, manifestações, condutas) são passíveis de transformarem-se em opinião pública desde o momento em que participem de maneira relevante ao exercício das funções estatais de dominação e administração. ${ }^{7}$

Ao abordar a temática da opinião pública no ciberespaço, Levy ${ }^{8}$ aduz a expansão e fragmentação da esfera pública. Assim, a opinião pública seria uma forma de qualificação de comunidades linguisticamente orientadas, ultrapassando a noção estatal e criando um espaço universal de formação e atualização de práticas discursivas, multiplicando-se dinamicamente os espaços públicos de discussão e, consequentemente, complexificando ainda mais tais discursos. 
É, contudo, a conceituação de opinião pública trazida por Luhmann a que melhor amolda-se aos objetivos do presente trabalho. A comunicação produz-se continuamente em uma rede hermético-recursiva, cujos componentes não são outra coisa senão comunicações. Nesse sentido, a comunicação é sensível a problemas constantemente gerados e complexificados, frente aos quais apresenta rápida reação. Basta referir-se os exemplos trazidos por Luhmann, ${ }^{\circ}$ como a consideração dos riscos das decisões, os problemas ecológicos, as conseqüências das novas tecnologias, etc.

Os meios de comunicação, a sua vez, operam distinções, ${ }^{10}$ atuam seletivamente indicando quais comunicações são passíveis de utilização, quais acontecimentos serão levados à público, etc. Os meios de massas proporcionam o acoplamento entre os diversos sistemas sociais. Logo, a linguagem, os meios eletrônicos, os meios de comunicação simbolicamente generalizados, etc, promovem continuamente 0 acoplamento e 0 desacoplamento dos sistemas e assim (re)produzem constantemente formas. ${ }^{11}$

Melhor expondo, a produção comunicativa no meio social é responsável pela produção da própria sociedade: tudo é comunicação ${ }^{12}$, as comunicações proporcionam e são proporcionadas por seus próprios meios autopoieticamente, gerando assim um excedente comunicativo apto a construção paradoxal da realidade social (forma, sim/não).

Os próprios meios de comunicação de massas são compreendidos enquanto uma forma baseada no código informação/não-informação. A opinião pública, nesse sentido, é o resultado da seletividade operada por estes meios. Assim, não são questionáveis eventuais manipulações ou distorções. A opinião pública enquanto produto de constantes atualizações dos meios de comunicação traduz-se como a própria realidade social, os meios geram constantemente descrições da realidade. ${ }^{13}$ Para Marcondes Filho,

\begin{abstract}
A lógica do pensamento atual não necessita mais da comprovação, da verificação fiel, da derrubada de argumentos. Este modelo está superado. A lógica atual é absolutamente outra: todo o instrumental "científico" é amplamente utilizado para dar status de verdade às imposições de classe e a opinião pública precisa apenas da aparência da verdade. O que lhe interessa é participar do jogo, fazer parte do espetáculo e não questionar os fundamentos últimos das explicações. ${ }^{14}$
\end{abstract}

Luhmann anota três dimensões pelas quais é possível descrever a seletividade dos meios de comunicação cujo resultado é o que se compreende enquanto opinião pública: a) na dimensão objetual ocorre uma quantificação de dados, um mapeamento do que pode ser utilizado como notícia; b) na perspectiva temporal é analisada a relevância do que se quer informar, a informação deve ser nova, deve possuir um valor informativo relevante, enquanto que na c) dimensão social ocorre certa mobilização social para gerir os conflitos, há uma constante produção de inquietude que torna por promover recorrentes operações sistêmicas para geri-las. ${ }^{15}$ 
Ilustrativamente pode-se redesenhar tais dimensões sob o prisma das notícias acerca dos casos de HIV no mundo, conforme relatórios da Organização das Nações Unidas. $\mathrm{Na}$ dimensão objetual são quantificados os dados acerca da ocorrência da doença no mundo. Posteriormente, na dimensão temporal é analisado se houve aumento ou diminuição da propagação da doença. Por fim, ante à dimensão social, a opinião pública torna por fazer emergir políticas pública, espelhadas neste caso nos programas de saúde com o intuito de controle das inquietações a qual o sistema social é submetido.

Saliente-se, de igual forma, as campanhas levadas adiante contra eventual epidemia de dengue no Brasil. Os meios de comunicação de massas tornam por fazer emergir um excedente comunicacional que acaba por ser moldado na opinião pública, dessa maneira viabilizam-se mobilizações, programas de prevenção à doença, movimentos educativos, etc. com vistas ao combate das causas da dengue, bem como de divulgação de informações para sua prevenção.

Por meio dessas três dimensões é possível a seleção informativa de modo à constituição da opinião pública. Após o levantamento daquilo que pode ser utilizado como notícia passa-se ao estudo da viabilidade do conteúdo a ser informado ao passo que, finalmente, a informação produzida torna por gerar inquietudes e perturbações que os sistemas absorvem e processam de acordo com seus próprios pressupostos sistêmicos.

Em outros termos, a opinião pública possibilita que o sistema político observe seu ambiente e os demais subsistemas e opere conforme o resultado dessa mesma observação. A opinião pública, pois, pode ser compreendida como um dos meios aptos à construção de formas no sistema social. Igualmente é compreendida enquanto possibilitadora de acoplamentos entre os diversos sistemas, viabilizando, com isso, a observação de segunda ordem enquanto praxis reflexiva sistêmica.

\section{REDES GERADORAS DE OPINIÃO PÚBLICA}

A sociedade é comunicação. Ao constituir-se comunicacionalmente, o sistema social torna-se o cenário propício à difusão comunicativa. É de ser lembrado que os meios de massa fornecem determinada indicação seletiva daquilo que é relevante e daquilo que não o é para o sistema social, bifurcando assim as possibilidades de descrição mediante a diferença informação/nãoinformação, restando a opinião pública como um produto de meios de comunicação de massas constantemente empenhados em fornecer descrições da realidade. Para Campilongo,

A sociedade pode ser examinada como uma rede de comunicações. O que diferencia o sistema social dos demais sistemas é exatamente isso. A operação típica da sociedade é a comunicação, entendida como ato de transmitir, receber e compreender a informação. A 
própria evolução sociocultural é exemplo da contínua transformação e ampliação das possibilidades de comunicação. ${ }^{16}$

Importa salientar, em um primeiro momento, o rompimento para com a visão cartesiana-mecanicista até então dominante no cenário científico. A fragmentação e redução às partes como forma de explicação do todo deve necessariamente ceder espaço à consideração de um todo interligado e interdependente. $O$ pensamento sistêmico, assim, passa a operar com 0 conceito de redes, de um todo interligado e harmonicamente operativo.

\begin{abstract}
$\mathrm{Na}$ visão mecanicista, o mundo é uma coleção de objetos. Estes, naturalmente, interagem uns com os outros, e, portanto, há relações entre eles. Mas as relações são secundárias [...]. Na visão sistêmica, compreendemos que os próprios objetos são redes de relações, embutidas em redes maiores. Para o pensador sistêmico, as relações são fundamentais. As fronteiras dos padrões discerníveis ("objetos") são secundárias [...]. ${ }^{17}$
\end{abstract}

Essa pequena noção de interligação e interdependência sistêmica é de extrema importância à compreensão da formação e disseminação da opinião pública no meio social. As redes geradoras de opinião pública operam de forma integrada, restando sua causa e efeito resultado e requisito de operações comunicativas anteriores, bem como sua corporificação no meio social condição de possibilidade a operações posteriores, conforme já referido anteriormente. Dessa maneira, a comunicação é constantemente produzida com base em outras comunicações.

Toda a comunicação é dependente de comunicações anteriores. De forma a ilustrar tal assertiva basta se pensar no fato ocorrido na África relacionado aos medicamentos destinados aos portadores de HIV: a decisão a favor da quebra de patentes de medicamentos ${ }^{18}$ teve repercussão mundial. Esse fato tornou por gerar um excedente comunicacional no âmbito do sistema social. ${ }^{19}$ Os meios de comunicação de massas, diferenciados mediante a codificação informação/não-informação, potencializaram a comunicação referente ao tema, tornando por influenciar a construção da opinião pública no sentido favorável à decisão que autorizou a quebra de patentes. llustrativamente, a opinião pública gerada por essa decisão tornou por causar ressonâncias ${ }^{20}$ na sociedade, viabilizando construções peculiares a cada sistema social mediante sua autopoiese própria.

Os meios de comunicação de massas, por isso, atuam imediatamente enquanto viabilizadores de descrições da realidade social. Dessa maneira sobressai cristalino o poder operado pelos media, no sentido de construção/desconstrução de comunicações e, conseqüentemente, da realidade social.

O processo da comunicação não está solto, e sim, inter-relacionado com outros meios. Para Nafarrate, "Os meios são precisamente isso: meios. Todo o peso da reflexão moderna sobre os meios de massa está centrado em uma crítica ao poder incontível e desumanizado ao homem" ${ }^{21}$. A realidade 
proposta aos meios de massas perpassa por uma crítica ao poder humano, assim, a

[...]comunicação em sua forma constitutiva primaria definida como código, como sistemas de diferenças - ou como se queira - não sente, não possui consciência, não valora, não discrimina; não é nem boa nem má para o ser humano, é simplesmente um fato cego. ${ }^{22}$

Na teoria luhmanniana, a sociedade é pura comunicação e toda a comunicação é sociedade, estando ambas completamente auto-ligadas. A comunicação não pode ser afetada por nada que exista fora dela, a sociedade é o universo de todas as comunicações possíveis. Por isso a comunicação é continuamente gerada em uma cadeia hermático-recursiva: comunicações produzem comunicações cuja existência somente é possível dentro dessa mesma rede. ${ }^{23}$

\begin{abstract}
A partir destas disposições gerais da teoria sistêmica e da teoria da sociedade, há que dar-se o passo seguinte para se chegar à teoria dos meios de comunicação para as massas. A função dos mass media consiste, sobretudo, em dirigir a autoobservação do sistema da sociedade - com isto não se está indicando nenhum objeto específico, mas a maneira na qual o mundo é cortado mediante a diferença sistema (é dizer sociedade/ambiente). Se trata de uma observação universal, e não uma observação específica de um objeto. ${ }^{24}$
\end{abstract}

Este avanço da comunicação para os meios de massa não significa a observação de um só objeto, mas sim a demonstração das diferenças existentes no mundo, garantindo "a todos os sistemas funcionais uma aceitação social ampla, e aos indivíduos a garantia de um presente conhecido, do qual possam partir para selecionar um passado específico ou expectativas futuras referidas aos sistemas" ${ }^{25}$. Percebe-se, na relação dos meios de massa com o tempo, que a "comunicação resolve em primeiro lugar um problema de tempo, e isto é válido para alguns meios de massa que operam sob pressão de aceleração. O problema é como se chega de uma comunicação a outra" ${ }^{26}$. A problemática proposta destaca o questionamento de como é feito o link das comunicações. Luhmann responde, dizendo:

Tudo isso seria impossível se dependesse de um consenso prévio, assegurado, e que fosse operativo. Ao contrário: cada comunicação explícita situa a pergunta por sua recepção ou rechaço; por conseguinte coloca o consenso em jogo, com pleno conhecimento de que se pode seguir comunicando através do dissenso. ${ }^{27}$

Cada comunicação trabalha com um código de recepção ou recusa, colocando o consenso em jogo, para que ela possa ser aceita ou não através da contradição. "Ao parecer, esta aplicação social dos meios de massa serva para entrelaçar permanentemente o passado com o futuro no marco das altas pretensões de redundância e variedade que exige a sociedade moderna, e que devem registrar de modo temporal" ${ }^{28}$.

Observa-se que na sociedade moderna se está lidando com relações de passado/futuro distintas de uma dimensão temporal, que é permitida pela da diferenciação e pelas clausuras operativas do sistema, que permitem seu 
fechamento e acoplamento. Assim, a função dos meios de massa é realizar na sociedade uma estrutura de bandas, ou seja, de reprodução e informação:

[...] estrutura dual entre prosseguimento da autopoiese viável e uma disposição aberta aos estímulos por parte da cognição. A preferência dos mass media, pelo valor de surpresa da informação, que ao ser publicada perde seu valor de informação, torna claro que a função dos meios de massas consiste na permanente produção e processamento dos estímulos - e não da difusão do conhecimento, nem sua socialização, nem a educação orientada a produzir conformidade com as normas. ${ }^{29}$

Essa estrutura de bandas propostas por Luhmann pode ser entendida como um sistema dual (AM (ondas médias) - FM (freqüência modulada), no qual tem-se duas bandas em que permite-se que sejam conectadas de acordo com sua freqüência. Essa estrutura produz a reprodução permanentemente, por meio do processamento de estímulos, e não sua socialização e educação de estabelecer uma resignação com as normas.

O fenômeno de auto-reprodução só é possível em razão de que "a comunicação somente é levada a efeito ali onde a auto observação, no ato de entender, distingue entre informação e ato de participar a comunicação. Sem esta distinção, a comunicação seria derrubada e os participantes se veriam constrangidos a perceber apenas comportamentos". ${ }^{30}$ Essa relação vislumbra a diferença "entre ato de participar da comunicação e informação se ajusta exatamente à exigência de que o prosseguimento da comunicação não reste dependente de que a informação seja total e adequada". ${ }^{31}$ Assim, há a exploração do mundo circundante pela comunicação, estabelecendo um patamar de (não)aceitabilidade com o entorno.

Por isso, "os meios de massas garantem a todos os sistemas funcionais uma aceitação social ampla, e aos indivíduos é garantido um presente conhecido, do qual possam partir para selecionar um passado específico ou expectativas futuras referidas aos sistemas". ${ }^{32}$ Essa relação propõe a possibilidade de estabelecer expectativas em relação ao futuro, refutadas no próprio sistema, através do meios de massa, desde que haja uma aceitação social, sempre na relação passado/futuro, no sentido de reduzir sua complexidade.

Pode-se entender que os meios de massa possuem um papel fundamental de conexão entre o passado e futuro, e que possibilitam a comunicação entre o sistema e entorno, com isso, gerando informação e, como conseqüência, opinião pública. Isso torna por gerar um excedente comunicacional pelo qual a sociedade obriga-se à realização de (auto)observações e (auto)descrições. Em suma,

A sociedade atual conhece a si própria através dos meios de comunicação de massa. Sua representação e sua operação dão-se sempre no presente. Os meios de comunicação tornam possível essa condição operativa da sociedade. Também tornam visível a simultaneidade de todas as operações que se realizam nos sistemas sociais da sociedade. ${ }^{33}$ 
A opinião pública, nesse sentido, é constantemente gerada e reformulada no ritmo em que os meios de massas proporcionam. A comunicação é propagada com uma velocidade avassaladora, restando a opinião pública em um contínuo movimento autopoiético. Por isso pode-se compreender que a própria sociedade, enquanto rede/sistema autopoiético comunicativo, alimenta os meios de comunicação de massas à constante construção da realidade social, sendo esta realidade refletida na opinião pública e pela opinião pública.

Pode-se assim dizer que todo e qualquer acontecimento comunicativo ocorre dentro da sociedade: apenas o sistema social possui capacidade de distinção das diversas comunicações mediante codificações próprias (sim/não). A diferenciação sistema/entorno mostra-se de extrema importância à compreensão da opinião pública, eis que toda comunicação, verse ela sobre o sistema, verse sobre o entorno, apenas é passível de existência no âmbito interno do sistema.

Os meios de comunicação operam mediante a distinção informação/não-informação. Ao passo em que o direito opera com conteúdos bifurcados em legal/ilegal, a política mediante a forma governo/oposição, etc. à comunicação interessa apenas aqueles enunciados com conteúdo informativo, pouco importando a legalidade, o valor econômico, a valoração política, 0 conteúdo educativo, etc. A informação é o elemento constituinte dos meios de comunicação, razão pela qual é projetada a realidade social mediante a possibilidade de observações de segunda ordem a serem operadas via opinião pública.

Precisamente por isto, depreende-se que a sociedade, através dos meios de comunicação, é uma imensa rede geradora de opinião pública: a comunicação constantemente selecionada é, repita-se, causa e efeito da constituição da realidade social. Nesse sentido todos os meios aptos à propagação da comunicação, como os meios de massas, os meios de comunicação simbolicamente generalizados, ${ }^{34}$ etc. operam distinções diante da rede comunicativa da sociedade, em um constante empenho em observar, descrever, construir e desconstruir a realidade social.

\section{CONDIÇÃO DE POSSIBILIDADE DA MUDANÇA SOCIAL}

A realidade social cotidiana é constantemente (re)construída, vive-se em um momento da história onde o tempo escapa com uma velocidade incrível e o espaço parece desdobrar-se em um só locus global. A pluralidade discursiva, levada adiante em uma pós-modernidade cada vez mais fragmentada e distante de metanarrativas, ${ }^{35}$ tornou por problematizar o Estado de forma até então inimaginada. O que antes era simples tornou-se complexo, - subjetivismo cedeu lugar ao descentramento do sujeito, passou-se à relativização do universal e abandonou-se a noção de segurança para adentrar-se nos debates acerca dos riscos. ${ }^{36}$ 
Essa problematização trouxe consigo a necessidade de se pensar em algo até então considerado de pouca importância. A sociedade voltou-se à consideração das conseqüências de decisões, corporificando-se o risco enquanto fator, ao mesmo tempo, de evolução social e democrática ${ }^{37}$ e de possibilidade danosa frente a tais decisões. ${ }^{38} \mathrm{Com}$ isso,

\begin{abstract}
A lógica da transformação da opinião pública, em particular sua fixação sobre posições conservadoras ou progressistas, isto é, a favor da troca ou da manutenção do status quo social, não está já a altura desta situação histórica. As questões devem delinear-se de outro modo. Dado que estamos imersos em uma veloz mudança social, é preciso questionar-se se devemos nos adaptar ou não às transformações; ou até que ponto sim e até que ponto não; ou se devemos fazer mais tarde ou mais cedo. Para dizer em outras palavras, se deve deixar que a mudança siga seu curso e adaptar-se depois a suas conseqüências quando a violência dos fatos assim o constranja? Ou há possibilidades de intervenções corretivas oportunas, que ainda assim não podem pretender controlar todo 0 acontecimento global desde um plano nem estão em condições de justificar-se como progresso? $?^{39}$
\end{abstract}

Assim, "vivemos num mundo de transformações, que afetam quase tudo o que fazemos. [...] estamos a ser empurrados para uma ordem global que ainda não compreendemos na sua totalidade, mas cujos efeitos já se fazem sentir em nós". ${ }^{40}$ Às transformações pelas quais atravessa o Estado e a sociedade não transparecem qualquer possibilidade de controle ou de determinação. Precisamente pelo fato de o sistema social apresentar-se como uma máquina não-trivial ${ }^{41}$ suas operações não podem ser programadas ou determinadas. Com isso, a sociedade caminha ao sabor da autopoiese sistêmica, na contínua (auto)manutenção e (auto)reprodução de suas estruturas. Para Luhmann,

A sociedade em que vivemos se vê sujeita a rápidas e profundas
transformações. Estas mudanças não somente afetam às formas nas
que se organiza a vida humana. Não somente abarcam o Estado e a
economia, as comunidades religiosas, o direito e a educação.
Abarcam também o meio natural e os motivos das pessoas e deste
modo revertem novamente sobre a sociedade. Não existe nenhuma
instância na sociedade capaz de guiar estas transformações em
direção a algum resultado global desejado; porém há muitas
possibilidades de influenciá-lo. ${ }^{42}$

Em meio a este aparente caos, não obstante a impossibilidade no que tange à determinação e/ou controle do caminho seguido pelo sistema social, conforme Luhmann há a possibilidade de influenciar a sociedade para seguir determinado caminho, ainda que o resultado de tal influência possa ser diverso daquele pretendido, afinal, por tratar-se de decisões, o fenômeno da contingência resta sempre presente. ${ }^{43}$ Dessa maneira, a opinião pública enquanto espelho da sociedade é passível de influência, isto é, sua construção deve ser dada de acordo com o que o requerido pelo sistema. 
A problemática referente à opinião pública reside justamente em sua construção. Luhmann acena para o fato de que a opinião pública se basta enquanto meio de descrição da realidade social, não importando o fundamento das comunicações ou a vontade individual, fato este que poderia ser interpretado como passividade frente a eventuais manipulações dos meios de comunicação de massas. Sob tal ótica a opinião pública deve ser compreendida enquanto um dado pronto e acabado, não sendo passível de questionamento ou eventuais revisões, afinal ela refletiria a verdade da sociedade, possibilitando observações e conseqüentes descrições com base em seu conteúdo.

Em verdade que a opinião pública reveste-se em um medium operados pelos meios de massa, todavia esse fato não exclui a possibilidade de influência nos meios de comunicação. É de ser destacada a possibilidade de insurgência popular em relação a determinada questão, gerando uma sobrecarga comunicativa que a sociedade deve identificar e absorver, mesmo que, ainda assim, a resposta apresentada pelos sistemas não necessariamente correspondam às expectativas populares.

Os meios de massas operam constantes distinções informativas, nesse sentido a opinião pública é moldada ao sabor de interesses por vezes alheios às necessidades da sociedade. A verdade da opinião pública torna-se a verdade da sociedade, não havendo espaço para críticas ou visualização de manipulações. Entretanto a construção da opinião pública deve ser dada de forma participativa e voltada a formas de descrição mais coesas com a realidade social. Assim, faz-se necessária a expansão de ambientes democráticos de discussão de modo à contínua transformação da opinião pública e, conseqüentemente, a constante mutação da sociedade.

\section{POLÍTICAS PÚBLICAS DE DEFESA DOS CONSUMIDORES}

Com o advento da lei 8.078 de 11 de setembro de 1990, o Brasil traz uma das mais avançadas leis de defesa dos consumidores, senão a melhor. Em seu art. $4^{0^{44}}$ Inc. II e IV, temos a atuação do Estado através de sua atuação direta ou indireta, com a criação de órgãos de defesa do consumidor, quer sejam eles estatais, através dos PROCON'S, ou pele fomento e apoio a criação de órgãos não governamentais, como por exemplo o IDEC ${ }^{45}$, Balcão do Consumidor - projeto da Faculdade de Direito da Universidade de Passo Fundo ${ }^{46}$.

A iniciativa do Balcão do Consumidor é uma parceria realizada entre o Município de Passo Fundo/RS e PROCON municipal, Ministério Público Estadual e Universidade de Passo Fundo, tendo atendido mais de 15.000 (quinze mil pessoas) desde sua fundação em 29 de setembro de 2006. Atuando não somente na resolução de conflitos. Mas também promovendo a política pública prevista no inciso IV do artigo 4ํำ do CDC, fazendo a educação para o consumo, através de cartilhas informativas, revista em quadrinhos com 
o personagem Tchê Consumidor, flyer's informativos, DVD com vídeo aulas, dicas no rádio e televisão, coluna em jornal de circulação local, realização de seminários e palestras.

Tal exemplo demonstra que é possível promover a mudança social através da educação para o consumo, divulgando a informação pelos mais diversos meios de comunicação e gerando a formação da opinião pública como forma de condição de possibilidade para a transformação da sociedade de consumo.

Cabe aos consumidores cobrarem de seus gestores a implementação para criação dos órgãos de proteção e defesa dos consumidores em seus municípios, fazendo que, com isso, mude a realidade do consumo e ocorra o respeito aos direitos dos consumidores.

\section{CONCLUSÃO}

Verifica-se que a opinião pública é um dos instrumentos mais poderosos para que se realize a transformação da realidade social, cabendo ao Estado o estabelecimento de políticas públicas criadoras de incentivos a sociedade, para que se criem os órgãos de proteção e defesa dos consumidores, no nível estatal através da criação de PROCON'S e na esfera privada, por meio da criação de entidades de proteção e defesa dos consumidores.

As Universidades tem um papel fundamental para o estabelecimento da promoção da educação para o consumo, pois são ações como a da Universidade de Passo Fundo, através do projeto Balcão do Consumidor é que estabelecem o elo de transformação da realidade social, através da sua inserção comunitária, levando a educação para o consumo aos seus cidadãos.

\section{OPINIÓN PÚBLICA Y POLÍTICA PÚBLICA DE EDUCACIÓN PARA EL CONSUMO: UNA HERRAMIENTA PARA LA TRANSFORMACIÓN DE LA REALIDAD SOCIAL.}

\section{RESUMEN}

El presente artículo versa sobre la transformación de la realidad social a través de la opinión pública y políticas públicas en la educación para el consumo. Por medio de este trabajo, se buscó analizar la conceituação de opinión pública, principalmente el concepto traído por Luhmann, que hace una conexión con los medios de comunicación y el proceso comunicativo, pues la opinión pública, mientras producto de constantes actualizaciones de los medios de comunicación, se traduce como la propia realidad social. ES en ese sentido, por lo tanto, que, para comprender la transformación de la realidad social, se pretende analizar las condiciones de posibilidad de cambio social, así como las políticas públicas de defensa de los consumidores, que irán a reflejar en la educación para el consumo. 


\author{
Palabras clave: Educación para el Consumo. Opinión Pública. \\ Políticas Públicas. Teoría de la Comunicación.
}

\title{
NOTAS
}

1. Doutor em Direito pela Universidade do Vale do Rio dos Sinos - UNISINOS (2008), Mestre em Direito pela Universidade de Santa Cruz do Sul - UNISC (2000). Possui graduação em Direito pela Universidade de Cruz Alta (1997). Professor dos cursos de Mestrado e Doutorado no Programa de Pós-Graduação Stricto Sensu em Ciência Jurídica da Universidade do Vale do Itajaí. Professor da Universidade de Passo Fundo. Tem experiência na área de Direito, com ênfase em Direito Constitucional, atuando principalmente nos seguintes temas: direito à saúde, direito internacional ambiental. Doutor em Direito pela UNISINOS.

SAUVY, Alfred. A opinião pública. 2. ed. São Paulo: Difel, 1966. p. 7.

PRICE, Vincent. Opinión publica. Barcelona: Paidós, 1994. p. 22.

4. LUHMANN, Niklas. La sociedad de la sociedad. México: Herder Editorial/Universidad Iberoamericana, 2007. p. 403: "[...] no puede hablarse de un concepto político de "opinión pública" antes de la segunda mitad del siglo XVIII, y de su imposición en toda Europa incluso después de la Revolución Francesa. Aunque la verdadera innovación se halla en el uso de le imprenta para poner en circulación panfletos políticos, o bien - en la Inglaterra del siglo XVII - para la divulgación de peticiones dirigidas al Parlamento. Porque con eso queda claro que no sólo se dirigen al destinatario y que estaba excluido el mantenerlas en secreto."

5. PRICE, Vincent. Opinión publica. Barcelona: Paidós, 1994. p. 22.

6. SARTORI, Giovanni. Homo Videns: televisão e pós-pensamento. Bauru: Edusc, 2001. p.52: "A opinião pública se apresenta antes de mais nada como uma situação, uma colocação. Neste sentido representa o conjunto de opiniões que se encontram na coletividade ou nos agregados públicos. Mas a noção de opinião pública consiste também e sobretudo nas opiniões generalizadas do público, nas opiniões endógenas, que são do público no sentido que o público é na verdade o sujeito das mesmas. Acrescente-se que uma opinião é dita pública não só porque pertence ao público, mas também porque envolve a res publica, a coisa pública, quer dizer, assuntos que são de natureza pública: o interesse geral, o bem comum, os problemas coletivos."

HABERMAS, Jürgen. Historia y crítica de la opinión pública: la transformación estructural de la vida pública. Barcelona: G. Gili, 2002. p. 268: "la opinión pública no está ya vinculada ni a reglas de discusión pública o a formas de verbalización, ni debe ocuparse de problemas políticos, ni menos aún dirigirse a instancias políticas. Su relación con la dominación, con el poder, aumenta, por así decirlo, a espaldas suyas: los deseos <<privados>> de automóviles y refrigeradores caen bajo la categoría de <<opinión pública >>, exactamente igual que el resto de modos de conductas de grupos cualesquiera con tal de que sean relevantes para el ejercicio de las funciones estatal- sociales de la dominación y la administración".

8. LÉVY, Pierre. Ciberdemocracia. Lisboa: Piaget, 2003. p. 53-54: "A opinião pública moldar-se-á cada vez mais em listas de discussões, fóruns, salas de conversação, redes de sítios interligados e outros dispositivos de comunicação próprios para as comunidades virtuais, dos quais alguns media clássicos serão quando muito, pontos de reunião. Neste enquadramento, o texto de um jornalista distinguir-se-á cada vez menos da opinião de um especialista de renome ou de um internauta de escrita fácil num grupo de discussão. A noção de opinião pública (a insistir na manutenção deste termo) qualificará prioritariamente comunidades lingüísticas e de afins diversos mais do que cidadãos de um Estado. [...] a esfera pública está em crescimento e em reorganização continuados. Ela desdobra-se, particulariza-se em pequenas e médias comunidades, cola-se aqui e acolá, floresce noutro ponto, reconstitui uma singularidade nesta ou naquela área do espaço semântico [...]. Em vez de apenas se multiplicarem num único nível, numa única escala (no palco clássico dos media), as suas formas, complexas e dinâmicas reproduzem-se em todas as escalas e No 35|P. 19-36| JAN-JUN 2011 
passam imprevisivelmente de um nível para outro no seio da rede viva, móvel e em expansão da inteligência coletiva da humanidade."

9. LUHMANN, Niklas. La sociedad de la sociedad. México: Herder Editorial/Universidad Iberoamericana, 2007. p. 869.

10. MARCONDES FILHO, Ciro. O escavador de silêncios: formas de construir e de desconstruir sentidos na comunicação: nova teoria da comunicação II. São Paulo: Paulus, 2004. p. 480.

11. MARCONDES FILHO, Ciro. O escavador de silêncios: formas de construir e de desconstruir sentidos na comunicação: nova teoria da comunicação II. São Paulo: Paulus, 2004. p. 476.

12. Ver LUHMANN, Niklas. O conceito de sociedade In: NEVES, Clarissa Eckert Baeta; SAMIOS, Eva Machado Barbosa (Org.). Niklas Luhmann: A nova teoria dos sistemas. Porto Alegre: Editora da Universidade/Goethe-Institut, 1997. p. 80; GARCÍA AMADO, Juan Antonio. La filosofía del derecho de Habermas y Luhmann. Bogotá: Universidad Externado de Colombia, 1997. p. 109-114.

13. LUHMANN, Niklas. La sociedad de la sociedad. México: Herder Editorial/Universidad Iberoamericana, 2007. p. 873.

14. MARCONDES FILHO, Ciro. Quem manipula quem? Poder e massas na indústria da cultura e da comunicação no Brasil. 5. ed. Petrópolis: Vozes, 1992. p. 14.

15. LUHMANN, Niklas. La sociedad de la sociedad. México: Herder Editorial/Universidad Iberoamericana, 2007. p. 872-874.

16. CAMPILONGO, Celso Fernandes. O direito na sociedade complexa. São Paulo: Max Limonad, 2000, p. 162.

17. CAPRA, Fritjof. A Teia da vida: uma nova compreensão científica dos sistemas vivos. 4. ed. São Paulo: Cultrix, 1999. p. 47.

18. Sobre as violações de garantias fundamentais por grandes empresas farmacêuticas transnacionais ver TEUBNER, Gunther. Globalized Society - Fragmented Justice: Human Rights Violations by "Private" Transnational Actors. In: ESCAMILLA, Manuel; SAAVENDRA, Modesto (Eds): Law and Justice in a global society. Granada: International association for philosophy of law end social philosophy, 2005.

19. Saliente-se a compreensão de sociedade enquanto um sistema global de comunicações, razão pela qual, em tempos de globalização, não é possível falar em unidades geograficamente delimitadas como fator de explicação de sociedades. Passa-se a falar da sociedade no lugar das sociedades. LUHMANN, Niklas; DE GIORGI, Raffaelle. Teoría de la sociedad. México: Universidad de Guadalajara/Univesidad Iberoamericana/ITESO, 1993. p. 69.

20. LUHMANN, Niklas. Ecological communication. Chicago: The University of Chicago Press, 1989. p. 15-21.

21. NAFARRATE, Javier Torres. In Memoriam. In: LUHMANN, Niklas. La realidad dos medios de masas. México: Anthropos Editorial. 2000. p. X: "Los medíos son precisamente eso: medios. Todo el peso de la reflexión moderna sobre los mass media está centrado en una crítica al poder incontenible y deshumanizado al hombre"

22. NAFARRATE, Javier Torres. In Memoriam. In: LUHMANN, Niklas. La realidad dos medios de masas. México: Anthropos Editorial. 2000. p. XII: "comunicación en su forma constitutiva primaria definida como código, como sistemas de diferencias - o como se quieira - no siente, no posee conciencia, no valora, no discrimina; no es ni buena ni mala para el ser humano, es simplesmente um suceso ciego"

23. LUHMANN, Niklas. The autopoiesis of social systems. In: GEYER, Felix.; ZOUWEN, Johannes van der (Eds.). Sociocybernetic paradoxes: observation, control and evolution of self-steering systems. London: Sage, 1986.

24. LUHMANN, Niklas. La realidad dos medios de masas. México: Anthropos Editorial. 2000. p. 39: "A partir de estas disposiciones generales de la Teoría de sistemas y de la Teoría de la sociedad, hay que dar el siguiente paso para arribar a la Teoría de los medios de comunicación para las massas. La función de los mass media consiste, por sobre todo, en dirigir la autoobservación del sistema de la sociedad - con esto no se está indicando ningún objeto específico, sino la manera en la que el mundo es cortado mediante la diferencia: sistema (es decir: sociedad/entorno). Se trata de una observación universal, y no una observación específica de un objeto." 
25. LUHMANN, Niklas. La realidad dos medios de masas. México: Anthropos Editorial. 2000. p. 142: "a todos los sistemas funcionales uma aceptación social amplia, y a los indivíduos les garantizan un presente conocido, del cual puedan partir para seleccionar un pasado específico o expectativas futuras referidas a los sistemas".

26. LUHMANN, Niklas. La realidad dos medios de masas. México: Anthropos Editorial. 2000. p. 143: "comunicación resuelve em primer lugar um problema de tiempo, y esto és válido para unos mass media que operan bajo presión de aceleramiento. El problema es cómo se llega de una comunicación a la otra"

27. LUHMANN, Niklas. La realidad dos medios de masas. México: Anthropos Editorial. 2000. 144: "Todo isto sería imposible si dependiera de um consenso prévio, asegurado, y que fuera operativo. Por el contrario: cada comunicación explícita situa la pregunta por su recepción o rechazo; por conseguinte pone el consenso en juego, a sabiendas de que se puede seguir comunicando a través del disenso".

28. LUHMANN, Niklas. La realidad dos medios de masas. México: Anthropos Editorial. 2000. p. 146: "Al parecer, esta aplicación social de los mass media sirve para entrelazar permanentemente el passado com el futuro en el marco de las altas pretenciones de redundância y variedad que exige la sociedad moderna, y que se deben registrar en modo temporal".

29. LUHMANN, Niklas. La realidad dos medios de masas. México: Anthropos Editorial. 2000. p.140: "[...] esctrutura dual entre prosecución de la autopoiesis viable y uma disposición abierta a los estímulos por parte de la cognición. La preferência de los mass media, por el valor de sorpresa de la información, que al ser publicada pierde su valor de información, hace claro que la función de los medios de masas consiste en la permanente produción y procesamiento de las estimulaciones - y no la difusión del conocimiento, ni su socialización, ni la educación orientada a producir conformidad con las normas"

30. LUHMANN, Niklas. La realidad dos medios de masas. México: Anthropos Editorial. 2000. p. 138: "la comunicación sólo se lleva a efecto allí donde la autoobservación, en el acto de entender, distingue entre información y acto de participar la comunicación. Sin esta distinción, la comunicación se derrumbaría y los participantes se verían constreñidos a percibir tan sólo comportamientos".

31. LUHMANN, Niklas. La realidad dos medios de masas. México: Anthropos Editorial. 2000. p.138: "entre acto de participar la comunicación e información se ajusta exactamente a la exigencia de que la prosecución de la comunicación no se hace dependiente de que la información sea total y adecuada".

32. LUHMANN, Niklas. La realidad dos medios de masas. México: Anthropos Editorial. 2000. p.142: "Los medios de masas garantizan a todos los sistemas funcionales una aceptación social amplia, y a los individuos les garantizan un presente conocido, del cual puedan partir para seleccionar un pasado específico o expectativas futuras referidas a los sistemas".

33. DE GIORGI, Raffaele. Direito, democracia e risco: vínculos com o futuro. Porto Alegre: SAFE, 1998. p. 38-39.

34. LUHMANN, Niklas. Poder. Brasília: UNB, 1985. p. 8: "O pressuposto primeiro e mais importante é que os processos de comunicação dirigidos pelos meios inter-relacionam os parceiros, que efetuam ambos operações seletivas próprias, tendo conhecimento simultâneo um do outro. Nós falaremos em Alter e em Ego. Todos os meios de comunicação pressupõem situações sociais com possibilidade de escolha para ambas as pares, situações, pois, com seletividade duplamente contingente. Á justamente isto que Ihes empresta a função de dirigir os processos de transmissão de seleções, em sua seletividade, do Alter para o Ego. Neste sentido, o problema inicial de todos os meios de comunicação generalizados simbolicamente é idêntico; para o poder vale, por conseguinte, tanto quanto para o amor ou para a verdade. Em todo caso, a comunicação que tem influência cada vez maior se relaciona sempre a um parceiro que deve ser dirigido em suas seleções."

35. Conforme LYOTARD, Jean-François. A condição pós-moderna. 6. ed. Rio de Janeiro: José Olympio, 2000, p. XV, entende-se por pós-modernidade a incredulidade em relação aos metarrelatos. Os grandes discursos enquanto meios aptos à explicação do homem e da natureza cedem lugar à uma pluralidade de vivências. Igualmente em VATTIMO, Gianni. Posmodernidad: ¿una sociedad transparente? In: VATTIMO, Gianni et. al. En torno a la posmodernidad. Barcelona: Anthropos Editorial, 2003. p. 10, tem-se a compreensão do rompimento de uma história centralizadora, cujos acontecimentos se davam sob sua 
onipresença. Passa-se de uma história unitária a uma pluralidade de vivências, de histórias concorrentes.

36. ARNAUD, André-Jean. O direito entre modernidade e globalização: lições de filosofia do direito e do Estado. Rio de Janeiro: Renovar, 1999. p. 202-203.

37. ROCHA, Leonel Severo. Direito, complexidade e risco. Seqüência, Florianópolis: Fundação Boiteux, n. 28, jun., 1994. p. 11.

38. Sobre o risco das decisões ver LUHMANN, Niklas. Sociología del riesgo. México: Triana Editores, 1998, onde é explicitado o risco enquanto produto exclusivo de decisões tomadas no sistema social. Toda e qualquer decisão é arriscada, em razão pela qual não seria possível mais se falar em segurança frente aos constantes riscos, mas partir-se para a diferenciação risco/perigo, enquanto distinção entre o produto de decisões e fatores alheios ao processo decisório. Nessa mesma linha, é de ser salientada a contribuição de BECK, Ulrich. La sociedad del riesgo: hacia una nueva modernidad. Barcelona: Paidós, 2001, onde o autor delimita as bases para a compreensão de uma sociedade de risco, moldada pelos crescentes avanços tecnológicos, cujos resultados voltam-se à coletividade enquanto possibilidade danosa. Ainda, em DE GIORGI, Raffaele. Direito, democracia e risco: vínculos com o futuro. Porto Alegre: SAFE, 1998. há a necessidade de a sociedade suportar riscos, ao contrário de supostas certezas quanto ao conteúdo das decisões. Nesse passo os riscos corporificam-se enquanto produto cujo potencial danoso deve ser assimilado pela sociedade. O risco é uma forma de distribuição dos bads e não dos goods.

39. LUHMANN, Niklas. Teoría política en el estado de bienestar. Madrid: Alianza Editorial, 2002. p. 149: "La lógica de la formación de la opinión pública, en particular su fijación sobre posiciones conservadoras o progresistas, es decir, a favor del cambio o del mantenimiento del status quo social, no está ya a la altura de esta situación histórica. Las cuestiones deben plantearse de otro modo. Dado que estamos inmersos en un veloz cambio social, es preciso cuestionarse si debemos adaptarnos o no a las transformaciones; o hasta qué punto sí y hasta qué punto no; o si debemos hacerlo más tarde o más temprano. Por decirlo en otras palabras, ¿se debe dejar que el cambio siga su curso y adaptarse después a sus consecuencias cuando la violencia de los hechos así lo constriña? ¿O hay posibilidades de intervenciones correctivas oportunas, que aún así no pueden pretender controlar todo el hecho global conforme a un plan ni están en condiciones de justificarse como progreso?"

40. GIDDENS, Anthony. O Mundo na era da Globalização. Lisboa: Presença, 2001. p. 15.

41. LUHMANN, Niklas. Novos desenvolvimentos na teoria dos sistemas. In: NEVES, Clarissa Eckert Baeta; SAMIOS, Eva Machado Barbosa (Org.). Niklas Luhmann: A nova teoria dos sistemas. Porto Alegre: Editora da Universidade/Goethe-Institut, 1997. p. 51: "Por 'máquina' entende-se simplesmente funções de transformação, não necessariamente aparelhos mecânicos, mas também cérebros ou cálculos matemáticos. Máquinas triviais transformam, sempre da mesma maneira, inputs em outputs. Se o input é repetido, obtémse o mesmo output - ou há um erro e a máquina precisa ir para o conserto. Máquinas autoreferenciais, ao contrário, tornam seu output dependente de seu respectivo estado, por exemplo, do estado que decorre das operações recém efetuadas. Elas produzem com os mesmos inputs, dependendo de sua própria situação, resultados completamente diferentes. Máquinas triviais são confiáveis e, conquanto que não defeituosas, operam de forma previsível. Máquinas auto-referenciais não são confiáveis, têm humor instável, são de certa forma máquinas históricas e podem, portanto, ser também criativas. Elas não podem, contudo, ser programadas para a criatividade. Elas não são previsivelmente criativas, mas sim aleatoriamente criativas."

42. LUHMANN, Niklas. Teoría política en el estado de bienestar. Madrid: Alianza Editorial, 2002. p. 147: "La sociedad en que vivimos se ve sujeta a rápidas y profundas transformaciones. Estos cambios no sólo afectan a las formas en las que se organiza la vida humana. No sólo abarcan al Estado y la economía, las comunidades religiosas, el derecho e la educación. Abarcan también al medio natural y a los motivos de las personas y de este modo revierten de nuevo sobre la sociedad. No existe ninguna instancia en la sociedad capaz de guiar estas transformaciones en dirección a algún resultado global deseado; pero hay muchas posibilidades de influenciarlo."

43. LUHMANN, Niklas. Sociologia do direito. v. I. Rio de Janeiro: Tempo Brasileiro, 1983. p. 45-46.

44. Art. 4ำ A Política Nacional das Relações de Consumo tem por objetivo o atendimento das necessidades dos consumidores, o respeito à sua dignidade, saúde e segurança, a 
proteção de seus interesses econômicos, a melhoria da sua qualidade de vida, bem como a transparência e harmonia das relações de consumo, atendidos os seguintes princípios: (Redação dada pela Lei oㅜ 9.008, de 21.3.1995)

45. [...]II - ação governamental no sentido de proteger efetivamente o consumidor:

a) por iniciativa direta; b) por incentivos à criação e desenvolvimento de associações representativas; c) pela presença do Estado no mercado de consumo; d) pela garantia dos produtos e serviços com padrões adequados de qualidade, segurança, durabilidade e desempenho.

b) IV - educação e informação de fornecedores e consumidores, quanto aos seus direitos e deveres, com vistas à melhoria do mercado de consumo;

$46 \quad$ IDEC - Instituto de Defesa do Consumidor.

47 [...] o projeto de extensão denominado Balcão do Consumidor, idealizado pelo professor Dr. Liton Lanes Pilau Sobrinho. Para sua concretização foi firmado convênio entre a Universidade de Passo Fundo, por intermédio da Faculdade de Direito, a Prefeitura de Passo Fundo (Procon) e o Ministério Público Estadual. O convênio estabeleceu que todo o atendimento preliminar encaminhado ao Procon passaria a ser feito por acadêmicos do curso de Direito, com a supervisão de professores. Após a abertura do procedimento junto ao Procon, o consumidor é atendido pelos alunos, que ouvem a demanda e registram as principais informações para, em seguida, manter um contato com o fornecedor buscando uma solução para o conflito. Quando não é possível chegar a um acordo com esse contato, que pode ser por telefone ou através de correspondência, é designada uma audiência extrajudicial, na qual são convocadas para estarem frente a frente todas as partes envolvidas. Chegando-se a uma solução, o caso é encerrado, ao passo que as situações em que isso não é possível o procedimento é encaminhado para o Procon, para que seja feito o processo administrativo. Além disso, o consumidor tem a liberdade de poder ingressar na Justiça, por intermédio de um profissional contratado, ou no Juizado Especial, nas causas com valor de até quarenta salários mínimos. seja feito o processo administrativo. Além disso, o consumidor tem a liberdade de poder ingressar na Justiça, por intermédio de um profissional contratado, ou no Juizado Especial, nas causas com valor de até quarenta salários mínimos. PILAU SOBRINHO, Liton Lanes; SILVA, Rogerio da. Balcão do consumidor: histórico do movimento consumerista em Passo Fundo. (Orgs.) - Passo Fundo: Ed. Universidade de Passo Fundo,2009. Pg58-59.

\section{REFERÊNCIAS}

ARNAUD, André-Jean. 0 direito entre modernidade e globalização: lições de filosofia do direito e do Estado. Rio de Janeiro: Renovar, 1999.

BECK, Ulrich. La sociedad del riesgo: hacia una nueva modernidad. Barcelona: Paidós, 2001.

CAMPILONGO, Celso Fernandes. O direito na sociedade complexa. São Paulo: Max Limonad, 2000.

CAPRA, Fritjof. A Teia da vida: uma nova compreensão científica dos sistemas vivos. 4. ed. São Paulo: Cultrix, 1999.

DE GIORGI, Raffaele. Direito, democracia e risco: vínculos com o futuro. Porto Alegre: SAFE, 1998.

GIDDENS, Anthony. O Mundo na era da Globalização. Lisboa: Presença, 2001. 
HABERMAS, Jürgen. Historia y crítica de la opinión pública: la transformación estructural de la vida pública. Barcelona: G. Gili, 2002.

LÉVY, Pierre. Ciberdemocracia. Lisboa: Piaget, 2003.

LUHMANN, Niklas. Ecological communication. Chicago: The University of Chicago Press, 1989.

. La realidad dos medios de masas. México: Anthropos Editorial. 2000.

. La sociedad de la sociedad. México: Herder Editorial/Universidad Iberoamericana, 2007.

Novos desenvolvimentos na teoria dos sistemas. In: NEVES, Clarissa Eckert Baeta; SAMIOS, Eva Machado Barbosa (Org.). Niklas Luhmann: A nova teoria dos sistemas. Porto Alegre: Editora da Universidade/Goethe-Institut, 1997.

O conceito de sociedade. In: NEVES, Clarissa Eckert Baeta; SAMIOS, Eva Machado Barbosa (Org.). Niklas Luhmann: A nova teoria dos sistemas. Porto Alegre: Editora da Universidade/Goethe-Institut, 1997. p. 80; GARCÍA AMADO, Juan Antonio. La filosofía del derecho de Habermas y Luhmann. Bogotá: Universidad Externado de Colombia, 1997. p. 109-114.

. Poder. Brasília: UNB, 1985.

Sociología del riesgo. México: Triana Editores, 1998.

. Sociologia do direito. v. I. Rio de Janeiro: Tempo Brasileiro, 1983.

2002.

Teoría política en el estado de bienestar. Madrid: Alianza Editorial,

The autopoiesis of social systems. In: GEYER, Felix.; ZOUWEN, Johannes van der (Eds.). Sociocybernetic paradoxes: observation, control and evolution of self-steering systems. London: Sage, 1986.

LUHMANN, Niklas; DE GIORGI, Raffaelle. Teoría de la sociedad. México: Universidad de Guadalajara/Univesidad Iberoamericana/ITESO, 1993.

LYOTARD, Jean-François. A condição pós-moderna. 6. ed. Rio de Janeiro: José Olympio, 2000.

MARCONDES FILHO, Ciro. $O$ escavador de silêncios: formas de construir e de desconstruir sentidos na comunicação: nova teoria da comunicação II. São Paulo: Paulus, 2004.

Quem manipula quem? Poder e massas na indústria da cultura e da comunicação no Brasil. 5. ed. Petrópolis: Vozes, 1992. 
NAFARRATE, Javier Torres. In Memoriam. In: LUHMANN, Niklas. La realidad dos medios de masas. México: Anthropos Editorial. 2000.

PILAU SOBRINHO, Liton Lanes; SILVA, Rogerio da. Balcão do consumidor: histórico do movimento consumerista em Passo Fundo. (Orgs.) - Passo Fundo: Ed. Universidade de Passo Fundo,2009.

PRICE, Vincent. Opinión publica. Barcelona: Paidós, 1994.

ROCHA, Leonel Severo. Direito, complexidade e risco. Seqüência, Florianópolis: Fundação Boiteux, n. 28, jun., 1994. p. 11.

SARTORI, Giovanni. Homo Videns: televisão e pós-pensamento. Bauru: Edusc, 2001.

SAUVY, Alfred. A opinião pública. 2. ed. São Paulo: Difel, 1966.

TEUBNER, Gunther. Globalized Society - Fragmented Justice: Human Rights Violations by "Private" Transnational Actors. In: ESCAMILLA, Manuel; SAAVENDRA, Modesto (Eds): Law and Justice in a global society. Granada: International association for philosophy of law end social philosophy, 2005.

Recebido para publicação: 08/08/2011

Aceito para publicação: 13/12/2011 